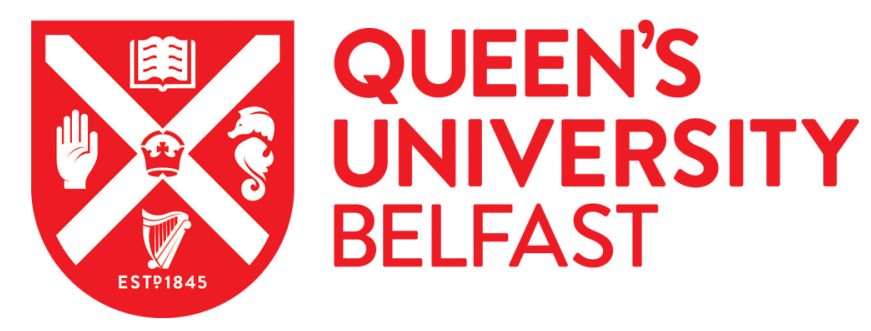

\title{
Acoustic and entropy waves in nozzles in combustion noise framework
}

Mahmoudi, Y., Dowling, A. P., \& Stow, S. R. (2017). Acoustic and entropy waves in nozzles in combustion noise framework. AIAA Journal. https://doi.org/10.2514/1.J055597

\section{Published in: \\ AIAA Journal}

\section{Document Version:}

Peer reviewed version

Queen's University Belfast - Research Portal:

Link to publication record in Queen's University Belfast Research Portal

\section{Publisher rights}

Copyright 2017 American Institute of Aeronautics and Astronautics, Inc.

This work is made available online in accordance with the publisher's policies. Please refer to any applicable terms of use of the publisher.

\section{General rights}

Copyright for the publications made accessible via the Queen's University Belfast Research Portal is retained by the author(s) and / or other copyright owners and it is a condition of accessing these publications that users recognise and abide by the legal requirements associated with these rights.

Take down policy

The Research Portal is Queen's institutional repository that provides access to Queen's research output. Every effort has been made to ensure that content in the Research Portal does not infringe any person's rights, or applicable UK laws. If you discover content in the Research Portal that you believe breaches copyright or violates any law, please contact openaccess@qub.ac.uk. 


\title{
Acoustic and entropy waves in nozzles in combustion noise framework
}

\author{
Y. Mahmoudi ${ }^{1}$, A. P. Dowling ${ }^{2}$ \\ University of Cambridge, CB2 1PZ Cambridge, UK \\ S. R. Stow ${ }^{3}$ \\ Rolls-Royce plc, Derby, DE24 8BJ, UK
}

\begin{abstract}
A low-order model is presented to study the propagation and interaction of acoustic and entropic perturbations through a convergent-divergent nozzle. The calculations deal with choked, unchoked, as well as compact and non-compact nozzles. In the choked case, a normal shock exists in the divergent section of the nozzle. To validate the models developed, cylindrical configurations corresponding to Entropy-WaveGenerator (EWG) and Hot-Acoustic-Testrig (HAT) of DLR are studied. For the EWG, an entropy wave is generated upstream of a nozzle by an electrical heating device, and for the HAT a speaker is used to generate pressure waves. In these two configurations and for the choked case, the supersonic region between the nozzle throat and the normal shock is assumed to be acoustically compact. The results of the low-order model are found to give excellent agreement with the experimental results of the EWG and HAT rigs. To give insight into the physics, the model is used to undertake a parametric study for a range of nozzle lengths and shock strengths. The low order model is finally used to calculate the direct to indirect (entropy and vorticity) combustion noise ratio for an idealised thin-annular combustor. For this model combustor the direct acoustic noise is found to dominate within the combustor while, the entropy indirect noise is found to be the main source of noise downstream of the choked nozzle. The indirect vorticity noise has a negligible contribution.
\end{abstract}

\section{Introduction}

COMBUSTION noise is becoming increasingly important as a major noise source in aircraft. This is partially because advances in the design of aircraft have reduced other noise sources such as jet, fan and external aerodynamic noise $[1,2]$. Furthermore, modern low-NOx combustors show a considerable increase in noise emission [3]. This is because lean premixed and stratified combustion burns more unsteadily and is also susceptible to an instability arising from the feedback interaction between unsteady combustion and acoustic waves $[4,5]$. Even when the self-excited instability has been eliminated by a careful combustor design, the combustor generates substantial broadband noise. It is therefore important to investigate this broadband combustion noise and develop methods to predict and reduce it.

The total noise radiated by a gas turbine combustion chamber system consists of 'direct' and 'indirect' combustion noise $[6,7]$. Fluctuation in heat release from the turbulent flame generates acoustic waves, and these and their reflections from the combustor boundaries constitutes the 'direct' combustion noise [7]. This noise propagates from the combustion chamber through the turbine and jet to the far field. The 'indirect' combustion noise is

\footnotetext{
${ }^{1}$ Research Associate, Department of Engineering, Trumpington Street.

${ }^{2}$ Professor, Department of Engineering, Trumpington Street. Fellow AIAA.

${ }^{3}$ Aerothermal Engineer, Combustion and Turbines Sub-System, Rolls-Royce plc.
} 
generated when the gas with a non-uniform entropy or vorticity distribution is accelerated, as it is when the unsteady products of combustion are convected through the nozzle located at the downstream outlet of the combustion chamber in a gas turbine [6]. Indirect noise in a similar way to the direct combustion noise can propagate through the turbine and also can reflect back into the combustor. It is often called 'entropy noise' and was first investigated analytically at low Mach numbers by the early works of Marble \& Candel [6] and Morfey [8] in the seventies. Combustion noise has been found to be important at low frequencies [9] and in the gas turbine geometry indirect noise dominates direct combustion noise at low frequencies $[1,10,11]$.In a detailed review by Morgans and Duran [12], five stages of flow physics have been identified as being important for entropy noise in gas turbines. These being (1) generation of entropy waves by unsteady heat release rate; (2) advection of entropy waves through the combustor (3) acceleration of entropy waves through nozzle guide vane and turbine blade rows that generates entropy noise (4) passage of entropy noise through a succession of turbine blade rows to appear at the turbine exit and (5) reflection of entropy noise back into the combustor, where it may further perturb the flame, causing the combustor thermoacoustic instability.

Previous studies have analysed the propagation and generation of sound by the passage of acoustic and entropy perturbations through a nozzle (e.g. [6, 13-18]). Marble \& Candel [6] considered linear, one-dimensional waves incident on a choked compact nozzle. The compact approximation works well when the nozzle is much shorter than all the wavelengths. The compact nozzle theory of Marble \& Candel [6] was extended by Cumpsty \& Marble $[19,20]$ and Cumpsty [21] to study entropy noise produced in a gas turbine at the combustor outlet and turbine blade stages. A significant increase of entropy noise generation was found with the increase of pressure drop over a turbine stage.

The compact solution of Marble \& Candel [6] has been extended to non-compact nozzles in the linear regime for choked nozzles with a shock [18, 22, 23], or with an isentropic supersonic expansion [24], and for subcritical nozzles [25]. Stow et al. [18] and Goh \& Morgans [22] used an asymptotic expansion of the linearized Euler equations to show that slightly non-compact nozzles can be modelled through use of an effective nozzle length that is slightly longer than the physical length. Stow et al. [18] studied both analytically and numerically the reflection of downstream propagating acoustic, entropic and vorticity waves incident on a choked exit nozzle. They found that the compact choked nozzle boundary condition of Marble \& Candel [6] is applicable even for circumferential waves in an annular geometry. Goh \& Morgans [22] used an asymptotic analysis of linearized Euler equations to determine analytical solutions to the nozzle response to incoming acoustic and entropic disturbances for the various flow configurations. For non-compact choked nozzles with a supersonic diffuser [24] 
and for subcritical non-compact nozzles [25], the linear transfer functions have been calculated numerically and analytically for the upstream and downstream acoustic waves generated by an incident entropy disturbance. Duran \& Morgans [26] studied numerically using high resolution 1-D and 2-D computations the propagation of circumferential waves (acoustic, entropy and vorticity waves) through an annular non-compact nozzle with isentropic mean flow throughout the divergent section of the nozzle (i.e. with no shocks). They concluded that circumferential entropy waves generate vorticity when accelerated. This vorticity wave originates due to the baroclinic torque as shown in the analytical study of Dowling \& Mahmoudi [1].

Comparison of the magnitudes of direct and indirect combustion noise requires an analysis of the linear waves generated by unsteady combustion to be coupled of their interaction in the nozzle. Leyko et al. [15] aimed to quantify the direct and indirect noise generated by unsteady combustion in a straight duct with a choked exit nozzle. They neglected any flow variation over the duct cross-section and also assumed that there was negligible mean heat input from the combustion so that the mean flow parameters upstream and downstream of the flame could be assumed to be equal. They also assumed that the mean flow is isentropic throughout a compact convergent-divergent nozzle. With those approximations, they showed that at low frequencies the approach of Marble \& Candel [6] agrees well with the numerical results obtained by solving the Euler equations. It was also found that [15] the ratio of indirect to direct noise is small for laboratory experiments but large in most real aeroengines, with the indirect noise exceeding the direct noise by one order of magnitude in real gas turbines but being negligible in most laboratory rigs [15]. Duran \& Moreau [23] studied numerically the ratio of indirect to direct noise for both subsonic and choked nozzles for different frequencies and again neglected any mean heat input. They studied the axisymmetric nozzle geometry of Bell et al. [10] and only considered the converging section, for simplicity. They found that for high frequencies, the ratio of indirect to direct noise decreases as frequency increases. This means that indirect noise is only significant at low frequencies and can be neglected at high frequencies.

It is difficult to experimentally separate direct and indirect combustion noise in practical configurations. This is partly due to the extreme operating conditions which makes measurement within the combustor difficult. In an attempt to separate the two noise sources, Muthukrishnan et al. [27] used coherence analysis to separate the two noise sources in a test rig of an aero-engine combustor. They found that if the combustor is choked at the exit the broadband indirect entropy noise is the principal source of the engine core noise. Bake et al. [28-30] revisited the problem on small-scale generic test rigs called Entropy Wave Generator (EWG) and Vorticity Wave Generator (VWG) [31]. They showed that small non-uniformities of temperature and vorticity can indeed generate 
significant noise when accelerated within a nozzle. Very recently in another experimental programme, DLR studied the noise generation in the Hot Acoustic Test rig (HAT) [32] by investigating the sound propagation through a nozzle and sound generation when cold air spots are injected into a hot mean flow. They found that the injection produces cold spots which propagate with the mean flow towards the nozzle and can produce noise. The amplitude of the pressure peak was found to depend linearly on the temperature difference between the cold spots and the mean flow when other flow parameters were kept constant [32].

The DLR EWG experiment has been investigated in a number of theoretical and numerical studies (e.g. [16, 33]). For an axisymmetric configuration, Leyko et al. [16] using the compact nozzle approximation of Marble \& Candel [6] and considering reflection from EWG rig outlet found excellent agreement between their analytical solution and experimental measurements. In addition to the choked isentropic nozzle studied by Leyko et al. [16] a subsonic configuration has been studied by Giauque et al. [25] and Duràn et al. [34]. The analytical results of Duràn et al. [34] based on a compact nozzle hypothesis for unchoked subsonic nozzle showed that the strength of the indirect noise is two orders of magnitude smaller than the direct noise. This finding suggested that the measured pressure waves at the outlet of EWG were not caused by entropy waves.

In a review Dowling \& Mahmoudi [1] analysed the magnitude of the indirect and direct noise sources generated due to a flame in an idealised combustor. To clarify the role of indirect noise they considered the outlet of the geometry to be either non-reflecting or choked and investigated the pressure perturbations within the combustor due to specified fluctuations in the rate of heat release at a range of frequencies. They found that compared to the non-reflecting outlet, the choked exit approximately doubles the magnitude of the direct pressure perturbation. The magnitude of the indirect vorticity noise found to be negligible compared to the direct acoustic and indirect entropy noise. They further showed that the resonances (caused by multiple reflections of waves between the choked nozzle and the heat release zone) that occur in the combustor can have significant effect particularly on the magnitude of the indirect entropy noise [1]. Ullrich \& Sattelmayer [35] studied an annular model combustor using hybrid CFD/CAA approach and reproduced the results obtained analytically by Dowling \& Mahmoudi [1]. For low frequencies they found very good agreement with the analytical solution of Dowling \& Mahmoudi [1], while for high frequencies due to insufficient grid resolution the agreement with the analytical solution was not so good. To provide sufficient grid resolution, high fidelity numerical simulations of turbulent reacting flows in complex geometries require substantial computational resources. Thus, prediction of the absolute level of combustion noise from a realistic combustor remains challenging. 
Thus, the main objective of the current work is to develop a simple low order model for the transmission and interaction of plane and circumferential waves through subsonic and supersonic compact nozzles, with and without shock. We study the acoustic response of a convergent-divergent nozzle to incident acoustic and entropic waves. By modelling the EWG and HAT rigs of DLR, we examine the application range of the low order model approach based on the compact nozzle approximation in predicting direct and indirect combustion noise in subsonic and supersonic nozzles. We further perform a parametric study (e.g. effect of shock strength and nozzle compactness) in EWG and HAT rigs on the dissipation and propagation of acoustic and entropic perturbations. Finally, the low order model developed will be used to predict the contribution of acoustic, entropic and vorticity perturbations created by the flame zone in the generation of noise at the outlet of an idealised combustor.

\section{Network modelling}

To analyse the linear acoustic, entropic and vortical perturbations in a complex geometry it is convenient to use a network model. We have used one such network model called LOTAN (Low-Order Thermo-Acoustic Network model), which has already been used extensively and is described in previous publications (e.g. [4, 18, 36]). LOTAN assumes a subsonic mean flow. We have extended it to deal with a choked convergent-divergent nozzle with, possibly, a shock in the divergent section. The geometry is modelled by a network of modules describing its features, such as straight ducts, area changes and heating zones. Quasi-steady conservation laws for mass, momentum and energy are used to relate flow perturbations across zones of heat input and across duct junctions. The application of inlet and outlet boundary conditions then enables determination of the linear perturbations. A perfect gas is assumed and the specific heats of $c_{p}, c_{v}$ and $\gamma$ are assumed to be temperature dependent as $c_{p}(T)=973.6+0.1333 \times T$, where $T$ is in $(\mathrm{K})$ and $c_{p}$ is in $\mathrm{J} / \mathrm{kg} \mathrm{K}[1]$.

We consider the form of perturbations that occur in a gap between two concentric cylinders. The straight annular duct is assumed to have cross-sectional area $a$, and the mean flow is axial and independent of radial or circumferential position. The flow is assumed to be inviscid, with pressure $p$, density $\rho$ and velocity $\vec{u}$. We will assume a perfect gas, $p=R_{\text {gas }} \rho T$, and so $T$ may be written in terms of $p$ and $\rho$. A linear disturbance in a straight duct can be thought of a sum of acoustic, entropy and vorticity waves. The acoustic waves propagate both upstream and downstream, while entropy and vorticity disturbances convect with the mean flow. Using cylindrical polar coordinates $(x, r, \theta)$ the velocity field is denoted by $\vec{u}=(u, v, w)$ and the duct has inner and outer radii of $r_{i}$ and $r_{o}$, respectively. In annular gas turbines, the radial gap $r_{o}-r_{i}$ of the combustor is typically much shorter than the circumference. In such situations we may approximate the flow by considering the case when the annular gap 
is narrow (i.e. $r_{i}-r_{o}$ is small in comparison with the acoustic wavelength and diameter,) with any variation of pressure in the radial direction negligible and the radial velocity $v$ zero [18].

The flow is taken to be composed of a steady axial mean flow denoted by an overbar and small perturbations denoted by primes, e.g. $p=\bar{p}(x)+p^{\prime}(x, \theta, t)$. The disturbances are assumed to have frequency $\omega$ in which the temporal dependence is of the form $e^{i \omega t}$. We restrict attention to positive $\omega$ without loss of generality. Furthermore, the angular dependence of the perturbations is taken to be of the form $e^{\text {in } \theta}$ with circumferential wavenumber $n$, which we will take to be a non-negative integer. Hence, we consider the disturbances to be of the form $p^{\prime}=\operatorname{Re}\left[\hat{p}(x) e^{i \omega t+i n \theta}\right]$ etc [37].

\section{Validation}

To demonstrate validity of this approach we have applied it to investigate the propagation of entropic and acoustic waves across the convergent-divergent nozzle in the Entropy-Wave-Generator (EWG-figure 1 in section III.A) [29] and Hot-Acoustic-Testrig (HAT- figure 5 in section III.B) [32] of DLR. For the EWG an entropy wave is generated upstream of the nozzle by an electrical heating device while for the HAT a loudspeaker is used to generate pressure waves. In both rigs the ducts have circular cross-section and we consider frequencies $\omega$ sufficiently low that all modes except the plane $(n=0)$ are cut-off.

We impose incident linear waves, acoustic, entropic or vortical from upstream onto the nozzle and wish to obtain the downstream-travelling acoustic, vorticity and entropy waves in the parallel section of the nozzle outlet at point 5 or 6 (see Fig. 1 for EWG, and Fig. 5 for HAT). The treatments first described the evolution of linear disturbances through the isentropic mean flow from 1 to 3 . They transferred into a frame reference in which the oscillating shock is at rest and applied the Rankine-Hugoniot equations in this moving frame to obtain the perturbations at position 4 . Subsequently, the isentropic flow in the region of area increase after shock from 4 to 5 was considered to obtain the perturbations in the straight duct at point 5 .

The convergent-divergent nozzles may be too long for the compact approximation to be valid for the full length of the nozzle at all frequencies of interest. So we model the converging section by short ducts of uniform cross-section connected by $M$ area changes of negligible length. The distance from the last area reduction to the choked throat needs to be compact. We assume that the region of supersonic flow between choked throat and the shock is compact, and the subsonic divergent section is modelled as a series of $N$ piece-wise area increases across which the flow is isentropic, with equal length straight ducts between them. 


\section{A. Incident entropy waves}

The Entropy Wave Generator (EWG) rig is shown schematically in figure 1 and the geometry and flow conditions are summarised in Table 1. The details of the experiment and the configuration are given [29]. For these mean inlet flow conditions, the effective sonic throat area is found to be $a_{t h r o a t}^{*}=\dot{m} \sqrt{R T_{0}} /\left(0.6847 p_{0}\right)=43.29 \mathrm{~mm}^{2}$ , giving an effective diameter of $7.42 \mathrm{~mm}$ compared to the geometrical throat diameter of $7.5 \mathrm{~mm}$. We interpret this difference to be due to boundary layers along the duct walls at the nozzle throat which reduces the effective nozzle area. The LOTAN solution predicts a shock with $\bar{M}_{3}=1.66$ at a location where $a_{3}=56.46 \mathrm{~mm}^{2}$. Suffix 3 denotes conditions just upstream of the shock.

Table 1 Physical parameters of EWG rig [29]

\begin{tabular}{lc}
\hline Mean pressure in the duct upstream of the nozzle $(0$ and 1) & $117 \mathrm{kPa}$ \\
\hline Mean pressure in the duct downstream of the nozzle $(5$ and 6$)$ & $100.8 \mathrm{kPa}$ \\
\hline Mean flow velocity in the duct upstream of the nozzle $(0$ and 1) & $12.18 \mathrm{~m} / \mathrm{s}$ \\
\hline Mean Mach number in the duct upstream of the nozzle $(0$ and 1) & 0.037 \\
\hline Mean Mach number in the duct downstream of the nozzle $(5$ and 6$)$ & 0.023 \\
\hline Mean Mach number at the nozzle throat $(2)$ & 1.0 \\
\hline Diameter of the nozzle throat used in LOTAN (2) & $7.42 \mathrm{~mm}$ \\
\hline Diameter of the duct upstream of the nozzle (0 and 1) & $30 \mathrm{~mm}$ \\
\hline Diameter of the duct downstream of the nozzle (5 and 6) & $40 \mathrm{~mm}$ \\
\hline
\end{tabular}

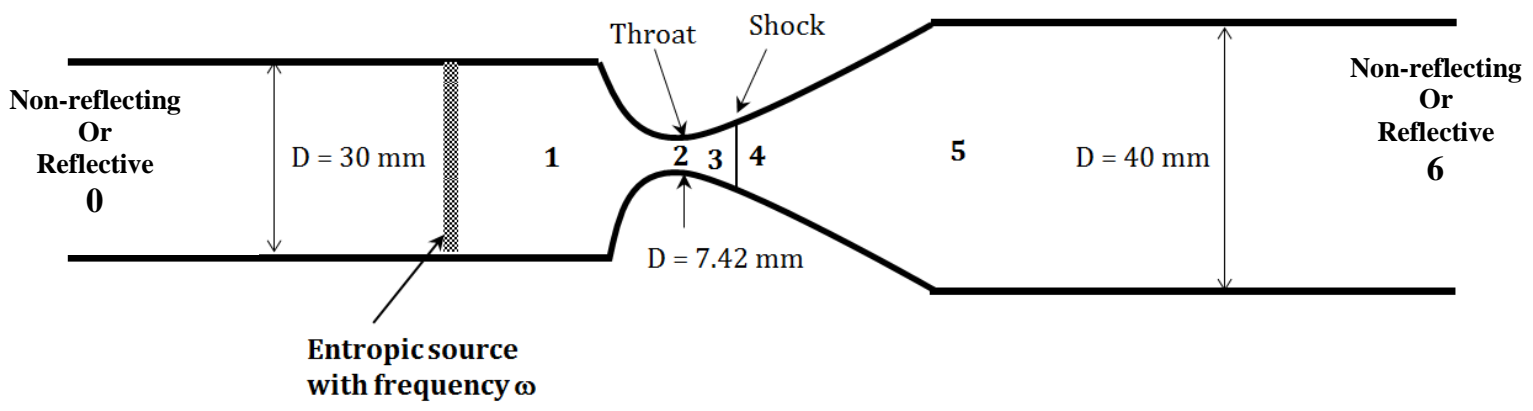

Fig. 1 Schematic diagram of EWG geometry used in LOTAN.

In the EWG an electric heating device located the upstream of the nozzle produces the temperature fluctuation shown in figure 2 . The pulse of temperature has a repetition rate of $1 \mathrm{~s}$. This temperature perturbation convects with the mean flow, accelerates through the nozzle, gets distorted and produces pressure fluctuations in both the upstream and downstream ducts. Results for the downstream pressure perturbation are shown in figure 3 . 


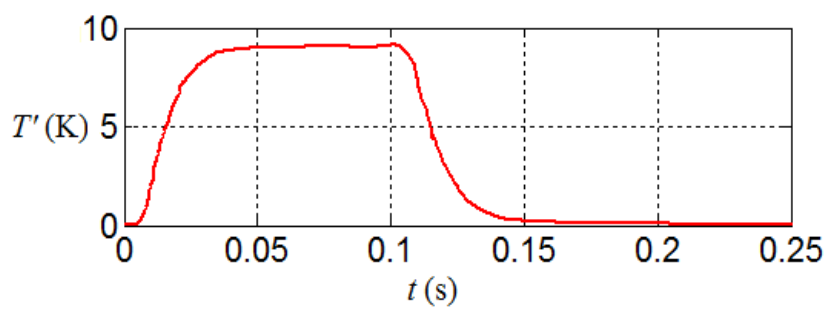

Fig. 2 Temperature fluctuation produced by heating device upstream of the nozzle [29].

Leyko et al. [16] performed analytical solutions and also a three-dimensional axisymmetric compressible Navier-Stokes simulation to model EWG rig. Leyko et al. [16] found that the duct exit of the EWG is not anechoic and the pressure wave reflected back towards the nozzle must be included. They determined this outlet pressure reflection coefficient to be $R_{6}=-1 /(i \omega / k+1)$, where the constant $k$ is $160 \mathrm{~s}^{-1}$ [16]. With this reflection coefficient they obtained excellent agreement with the experimental results. We use the same outlet reflection coefficient in LOTAN. The results are obtained by performing a series of frequency-domain calculations using LOTAN to obtain the transfer function due to an entropy wave incident onto the nozzle. Then using a Green's function approach [36] the time trace of the pressure was computed via an inverse Fourier transform. Results from LOTAN for $750 \mathrm{~mm}$ downstream of the throat (red line) are shown in figure 3 where they are compared with the results of Leyko et al. [16] and experimental signal of EWG. The agreement is excellent.

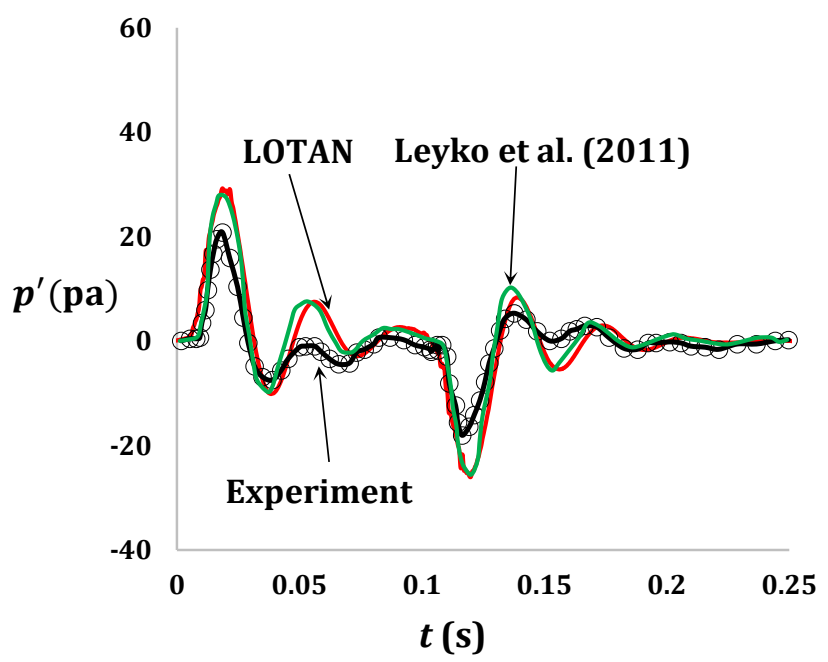

Fig. 3 Pressure fluctuation at $750 \mathrm{~mm}$ downstream of the nozzle throat for LOTAN computation (red line), Leyko et al. [16] (green line) using a reflective boundary condition at the outlet compared with the experiment of EWG [29] (black line with symbols).

As discussed above the subsonic divergent and convergent sections of the nozzle are modelled respectively as $M$ piece-wise area decreases and $N$ area increases with straight duct sections between them. To make sure that the 
results obtained are independent of $M$ and $N$, the calculations were repeated for $(M, N)=(1,2),(2,5),(4,10)$ and $(8,20)$. The LOTAN results are indistinguishable. For the temperature pulse in figure 2 , the excitation frequencies are below $100 \mathrm{~Hz}$ and the compact approximation is valid across the nozzle.

In order to study the effects of the shock strength on the acoustic wave generated, we performed calculations for different values of the mean pressure at the outlet of EGW rig which leads to shocks of different strengths and different mean outlet Mach number $\bar{M}_{5}$. Figure 4 shows that changing the shock strength only has a small effect on the pressure signal.

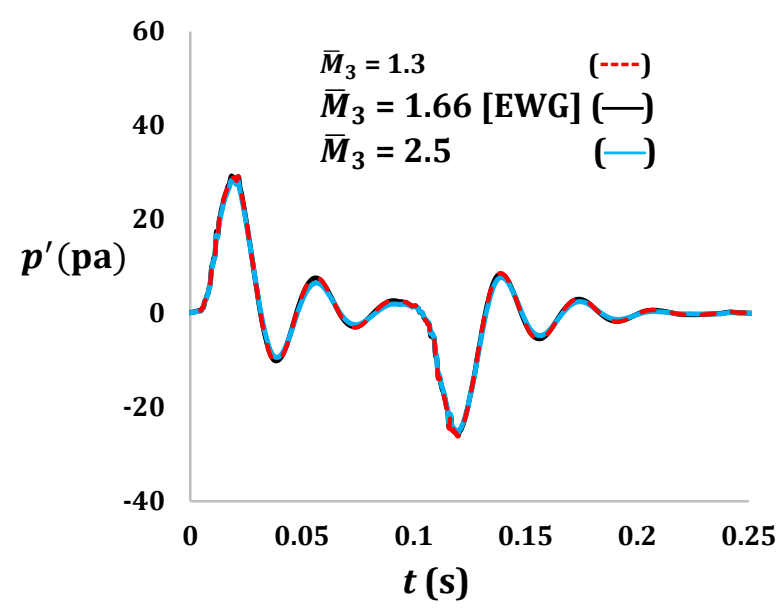

\section{Fig. 4 Pressure fluctuation obtained using LOTAN at $750 \mathrm{~mm}$ downstream of the nozzle with} different shock strengths.

For the EWG rig the frequency studied is very low up to $100 \mathrm{~Hz}$. With an average speed of sound of $320 \mathrm{~m} / \mathrm{s}$ in the nozzle the wavelength is about $3200 \mathrm{~mm}$. Such wavelength is even longer than the whole nozzle length of $263 \mathrm{~mm}$ and hence the nozzle can be treated as compact. For the shock strength studied here the mean outlet Mach number $\bar{M}_{5} \approx \mathrm{O}\left(10^{-2}\right)$ and hence is negligible compared to 1 . Therefore, the analytical solution for acoustic transfer function presented by Moase et al. [24] simplifies to $t^{+}=A_{+5} / A_{+1}=0.29\left(a_{5} / a_{\text {throat }}^{*}\right)^{-1}$, where $A_{+1}$ and $A_{+5}$ represent the amplitudes of the downstream travelling acoustic waves upstream and downstream of the choked nozzle, respectively. This indicates that for a compact nozzle and very low Mach number flows in the upstream and downstream straight ducts the transmission coefficient is independent of shock strength and is only a function of nozzle geometry and mean inlet Mach number.

\section{B. Incident acoustic waves}

The DLR HAT rig shown schematically in figure 5 has an inner diameter of $70 \mathrm{~mm}$ and a total length of about $5.4 \mathrm{~m}$. The nozzle has a throat diameter of $30 \mathrm{~mm}$ and an overall length of about $400 \mathrm{~mm}$. The operating conditions 
are given in Table 2. Case 1 yields a choked nozzle with a weak normal shock in the divergent section just downstream of the throat. For Case 2 the mean flow is subsonic throughout the nozzle with a maximum Mach number of 0.67 at the nozzle throat.

Table 2 Physical parameters of HAT rig [32]

\begin{tabular}{l|cc}
\multicolumn{1}{c|}{ Parameter } & Case 1 & Case 2 \\
& $\left(\bar{M}_{\text {throat }}=1.0\right)$ & $\left(\bar{M}_{\text {throat }}=0.67\right)$ \\
\hline Mean pressure in the upstream duct (0 and 1) & $105.59 \mathrm{kPa}$ & $102.58 \mathrm{kPa}$ \\
\hline Mean pressure in the downstream duct (5 and 6) & $100.05 \mathrm{kPa}$ & $99.98 \mathrm{kPa}$ \\
\hline Mean mass flow rate (0 and 1) & $0.1331 \mathrm{~kg} / \mathrm{s}$ & $0.1162 \mathrm{~kg} / \mathrm{s}$ \\
\hline Mean temperature in the upstream duct (0 and 1) & $473 \mathrm{~K}$ & $473 \mathrm{~K}$ \\
\hline Mean Mach number in the upstream duct (0 and 1) & 0.103 & 0.092 \\
\hline Mean Mach number at the nozzle throat (2) & 1.0 & 0.67 \\
\hline Mean Mach number in the downstream duct (5 and 6) & 0.107 & 0.093 \\
\hline Diameter of the nozzle throat used in LOTAN (throat) & $29.4 \mathrm{~mm}$ & $29.4 \mathrm{~mm}$ \\
\hline Diameter of the upstream duct (0 and 1) & $70 \mathrm{~mm}$ & $70 \mathrm{~mm}$ \\
\hline Diameter of the downstream duct (5 and 6) & $70 \mathrm{~mm}$ & $70 \mathrm{~mm}$ \\
\hline
\end{tabular}

In the experiments, characterization of the acoustic properties of the nozzle, primarily the transmission and reflection and its dependence on nozzle Mach number was done using sufficient microphones and loudspeaker excitation, so that the data could be post-processed to obtain the pressure transmission $\left(t^{+}\right)$and reflection coefficient $\left(r^{+}\right)$due to an acoustic wave $A_{+1} e^{i \omega\left(t-x /\left(\bar{c}_{1}+\bar{u}_{1}\right)\right)}$ incident onto the nozzle from upstream:

$$
\begin{aligned}
& r^{+}=A_{-1} / A_{+1}, \\
& t^{+}=A_{+5} / A_{+1} .
\end{aligned}
$$

The indexes 1 and 5 refer to upstream and downstream of the nozzle as illustrated in figure 5 . The suffices + and - denote the downstream and upstream travelling acoustic waves, respectively. $\mathrm{R}$ and $\mathrm{T}$ express the reflection and transmission in terms the coefficients for the acoustic energy flow rates $P^{ \pm}=(a / 2 \bar{\rho} \bar{c})(1 \pm \overline{\mathrm{M}})^{2}\left|A^{ \pm}\right|^{2}$,

$$
\begin{gathered}
\mathrm{R}^{+}=\frac{P_{1}^{-}}{P_{1}^{+}}=\frac{\left(1-\overline{\mathrm{M}}_{1}\right)^{2}}{\left(1+\overline{\mathrm{M}}_{1}\right)^{2}}\left|r^{+}\right|^{2}, \\
\mathrm{~T}^{+}=\frac{P_{5}^{+}}{P_{1}^{+}}=\frac{a_{5}}{a_{1}} \frac{\bar{\rho}_{1} \bar{c}_{1}}{\bar{\rho}_{5} \bar{c}_{5}} \frac{\left(1+\overline{\mathrm{M}}_{5}\right)^{2}}{\left(1+\overline{\mathrm{M}}_{1}\right)^{2}}\left|t^{+}\right|^{2} .
\end{gathered}
$$

$\overline{\mathrm{M}}$ is the mean Mach number. $\bar{\rho}$ and $\bar{c}$ denote respectively the local mean density and sound speed. In the HAT rig, the cross-sections of the measurement sections area equal, so that $a_{1}=a_{5}$.

Similar to the model developed for EWG in section (III.A) we assume that convergent and divergent sections of the nozzle are modelled by $M$ and $N$ 'area decrease' and 'area increase' modules, respectively. 


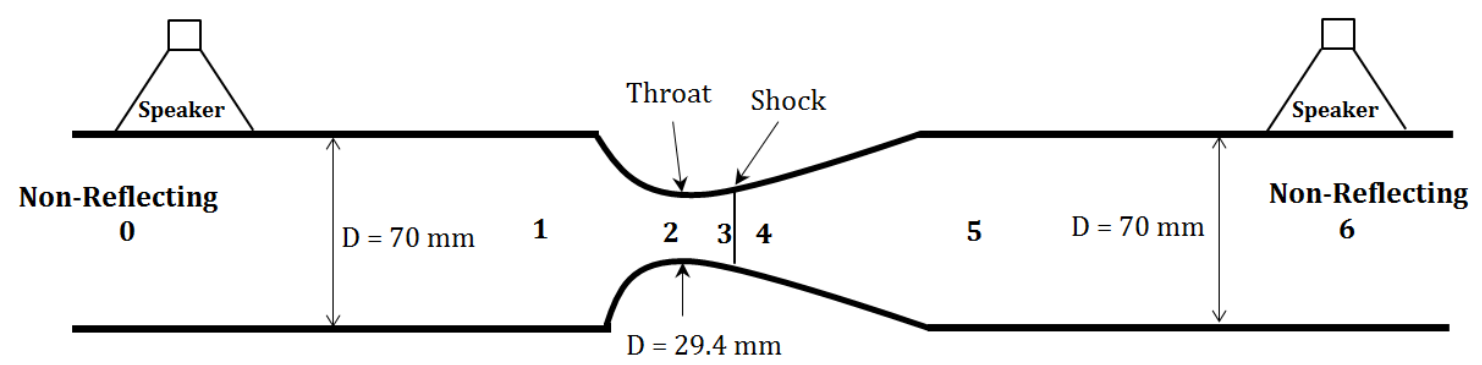

Fig. 5 Schematic diagram of HAT geometry used in LOTAN.

To make sure that the results obtained are independent of the number of $M$ and $N$, the computations were performed for various $M$ and $N$ numbers. $N=40$ and $M=8$ is used as a sufficient number of segments to describe the divergent and convergent sections of the duct. In the experiment, the nozzle was found to be choked at the throat with diameter of $30 \mathrm{~mm}$. While, for the flow properties given in Table 2 for Case 1 we find the throat area where the Mach number is 1 found to be $a_{\text {throat }}^{*}=676.54 \mathrm{~mm}^{2}$ with diameter of $29.4 \mathrm{~mm}$. Similar to EWG rig this implies that boundary layers within the nozzle which reduces the effective throat area. Thus, in our low-order model the throat diameter is set to be $29.4 \mathrm{~mm}$. Using gas dynamic relations the mean flow conditions of HAT rig are presented in Table 3. For this rig LOTAN predicts that a strong shock wave with $\bar{M}_{3}=1.4$ at a position with $a_{3}=755.66 \mathrm{~mm}^{2}$.

Table 3 Some mean flow properties of HAT rig

\begin{tabular}{ccccccccc}
\hline $\bar{p}_{5} / \bar{p}_{1}$ & $\bar{p}_{4} / \bar{p}_{1}$ & $\bar{T}_{4} / \bar{T}_{1}$ & $\bar{M}_{1}$ & $\bar{M}_{\text {throat }}$ & $\bar{M}_{3}$ & $\bar{M}_{4}$ & $\bar{M}_{5}$ & $a_{3} / a_{\text {throat }}^{*}$ \\
\hline 0.95 & 0.66 & 0.90 & 0.103 & 1.0 & 1.41 & 0.74 & 0.107 & 1.12 \\
\hline
\end{tabular}

Figure 6 shows the energy reflection $\left(\mathrm{R}^{+}\right)$of a downstream-propagating acoustic wave incident onto the nozzle from upstream. The results predicted using LOTAN for the energy reflection coefficient $\mathrm{R}^{+}$are shown in figure 6 and compared with the experimental measurements on the HAT rig in Knobloch et al. [32].

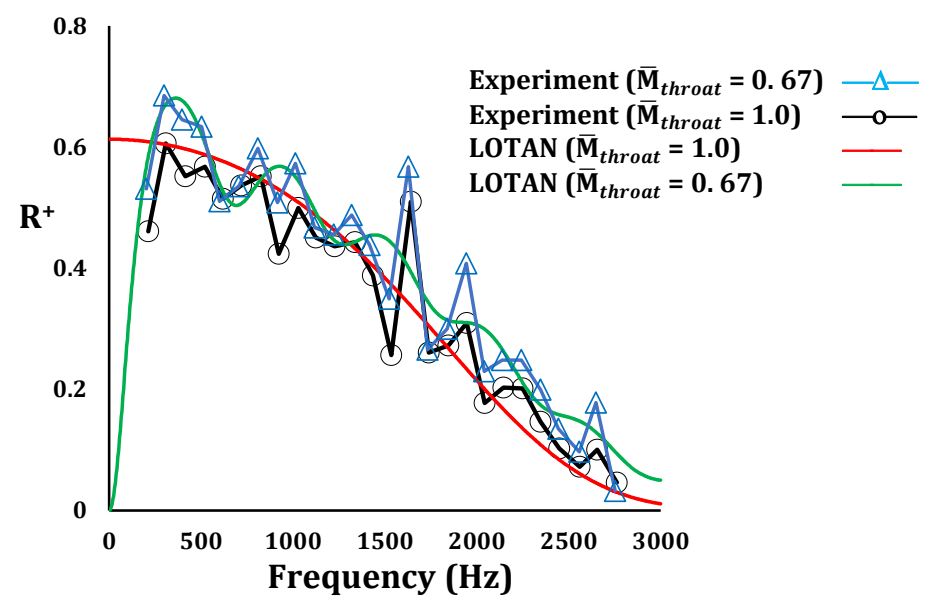


Fig. 6 Energy reflection coefficient of the nozzle as a function of frequency obtained using LOTAN for Case 1 choked nozzle (red line), and Case $2 \bar{M}_{\text {throat }}=0.67$ (green line) compared to experimental results of HAT rig from Knobloch et al. [32] (lines with symbol).

The results obtained using LOTAN are in excellent agreement with experimental measurements. For Case 1 with a choked nozzle the low frequency pressure reflection coefficient is $r^{+} \rightarrow\left(1-\bar{M}_{1}(\gamma-1) / 2\right) /\left(1+\bar{M}_{1}(\gamma-1) / 2\right)$ as $\omega$ tends to zero [18]. Thus, using (3.3) with $\bar{M}_{1}=0.103$, we obtain $\mathrm{R}^{+} \rightarrow 0.6$. It is clearly visible that for high frequencies, at which the incoming acoustic waves have shorter wavelengths, the nozzle is no longer a severe obstacle and the reflection coefficient tends to zero. For comparison the refection coefficients for an unchoked nozzle are influenced by the cross-sectional area and the mean flow conditions at the nozzle exit and also by the geometry of the nozzle divergence when it is non-compact. Therefore the results for Case $2\left(\bar{M}_{\text {throat }}=0.67\right)$ have a more complicated dependence on frequency than the choked case which simply decreases gradually with frequency. It has multiple peaks and troughs due to resonances of the divergent section. For very low frequencies when $\omega \rightarrow 0$, the nozzle is compact and since the duct areas are equal on either side, the sound wave propagates through unchanged and $\mathrm{R}^{+} \rightarrow 0$. This is in contrast to the choked nozzle case for which for low frequencies the reflection coefficient tends to a finite non-zero value.

The energy transmission coefficient, $\mathrm{T}^{+}$, for an acoustic wave incident from upstream onto the nozzle is obtained using (3.4) and the results predicted by LOTAN for choked and unchoked nozzles are shown in figure 7 and compared with the HAT experimental results. In both cases the predictions are in excellent agreement with experiment. For the choked nozzle Case1, the low frequency transmission coefficient is small.

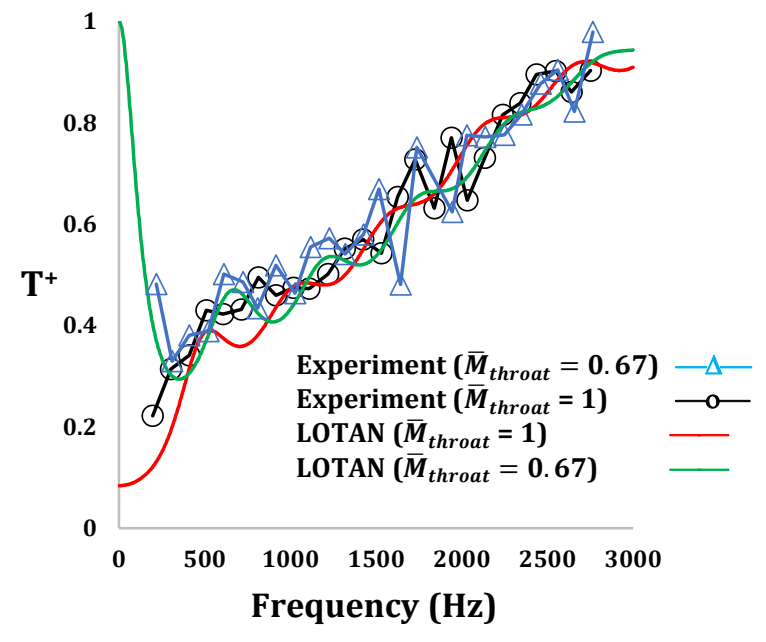

Fig. 7 Energy transmission coefficient of the nozzle as function of frequency obtained using LOTAN for Case 1 choked nozzle (red line), Case $2 \bar{M}_{\text {throat }}=0.67$ (green line) compared to experimental results of HAT rig from Knobloch et al. [32] (black line with symbol). 
As the frequency increases less energy is reflected from the nozzle convergence and more acoustic energy is transmitted downstream and thus $\mathrm{T}^{+}$increases with frequency. In contrast, for the subsonic nozzle Case 2 , it is seen that for very low frequencies the energy transmission coefficient $\mathrm{T}^{+}$tends to 1 . This is because when the nozzle is compact and there is no shock, the waves pass straight through the nozzle as here the upstream and downstream ducts have the same area. Hence, we expect all the acoustic energy to be transmitted through the nozzle.

The acoustic energy dissipation coefficient $\left(\Delta^{+}=1-\mathrm{R}^{+}-\mathrm{T}^{+}\right)$for an acoustic wave incident on the nozzle from upstream is shown in figure 8 . Since $\Delta^{+}$is the small difference between $\mathrm{O}(1)$ terms some inaccuracy is observed in experimental measurements which vary abruptly from frequency to frequency. Nevertheless for the choked case the predicted trends are in reasonable agreement with experiment. Both have significant acoustic energy dissipation at low frequency.

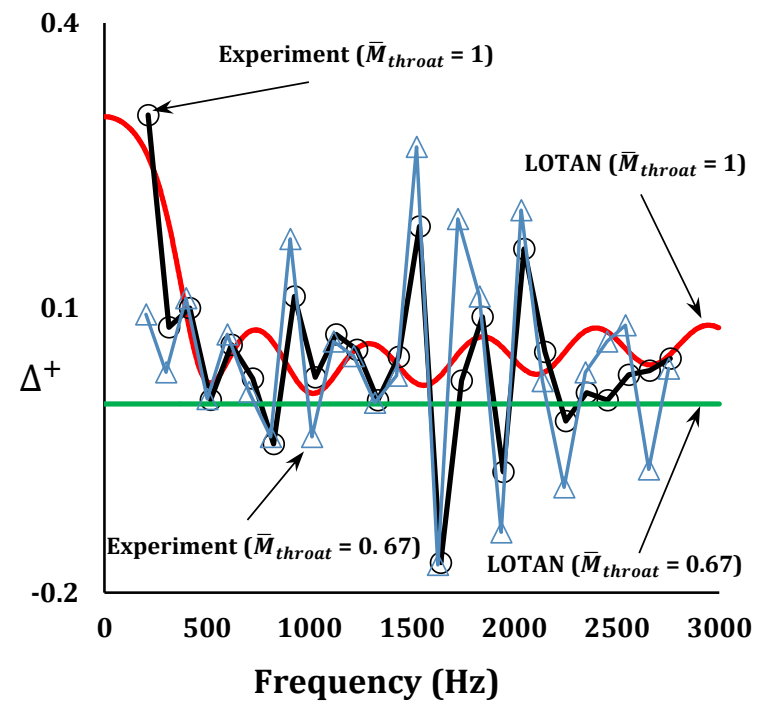

Fig. 8 Acoustic energy dissipation coefficient $\left(\Delta^{+}=1-\mathbf{R}^{+}-\mathrm{T}^{+}\right)$as a function of frequency obtained using LOTAN for Case 1 choked nozzle (red line), Case $2 \bar{M}_{\text {throat }}=0.67$ (green line) compared to experimental results of HAT rig from Knobloch et al. [32] (black line with symbol).

For the choked case the dissipation of acoustic energy is due to its interaction with the shock wave $\left(\bar{M}_{3}=1.4\right.$ ) in the divergent section of the nozzle where acoustic energy can be converted into convecting entropy fluctuations. For the unchoked Case 2, the flow in LOTAN is modelled as isentropic and so the dissipation is predicted to be zero for all frequencies. Some dissipation is measured in the experiment and would be due to viscous effects, flow separation in the nozzle, or experimental error. 


\section{Parametric study - effect of shock strength}

To clarify the role of the shock strength in the transmission and dissipation of acoustic energy the computations have been performed for different shock strengths by changing the mean pressure at the rig outlet. Figures 9(a) and 9(b) show the energy transmission and dissipation coefficients, respectively, for normal shocks with $\bar{M}_{3}=1.22, \bar{M}_{3}=1.41, \bar{M}_{3}=1.68, \bar{M}_{3}=2.0$ and $\bar{M}_{3}=2.23$. It is seen that for a fixed frequency as the shock strength increases the energy transmission coefficient decreases. This is because of the increasing dissipation of acoustic energy due to the stronger shock wave as shown in Figure 9(b). These figures also show that the effect of shock wave on dissipation and transmission of acoustic energy is more significant at high frequencies. For frequencies below about $500 \mathrm{~Hz}$ changing the shock strength has no noticeable effect on the acoustic energy.

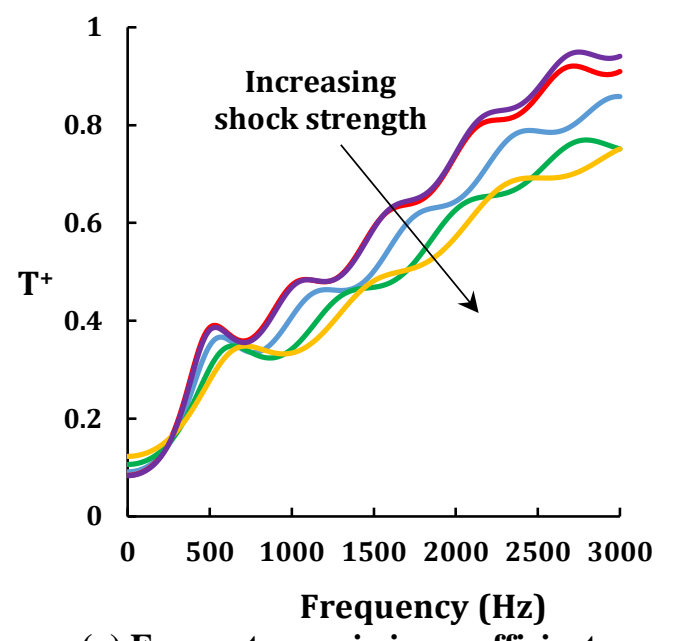

(a) Energy transmission coefficient

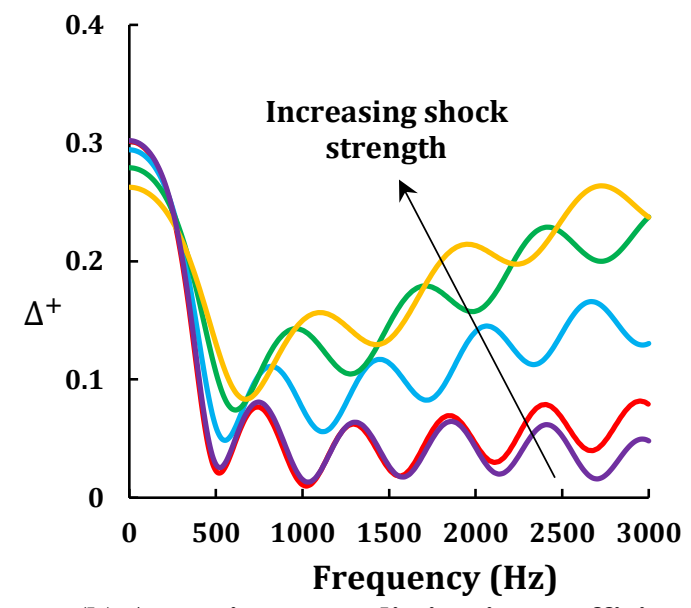

(b) Acoustic energy dissipation coefficient

Fig. 9 (a) Energy transmission and (b) dissipation coefficients of the nozzle as a function of frequency obtained using LOTAN for the HAT rig with different exit pressures and hence different shock strengths, $\bar{M}_{3}=1.22$ (purple line) $\bar{M}_{3}=1.41$ (red line), $\bar{M}_{3}=1.68$ (blue line), $\bar{M}_{3}=2.0$ (green line) and $\bar{M}_{3}=2.23$ (yellow line). 


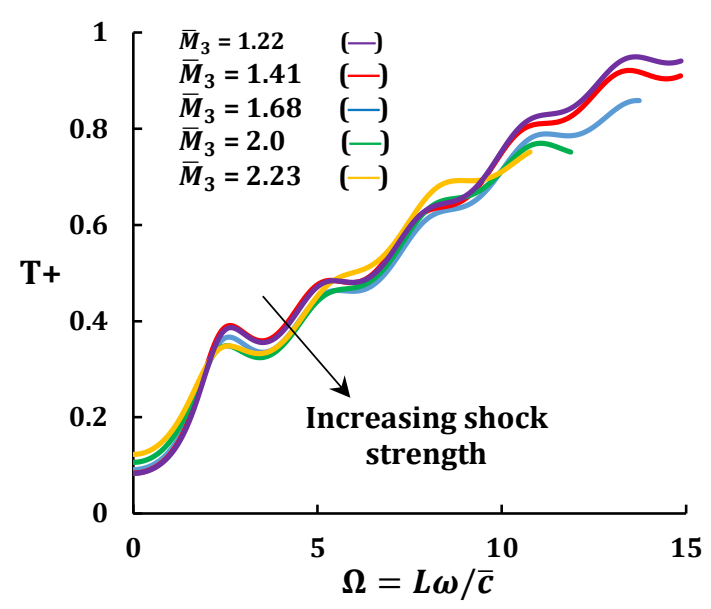

Fig. 10 Energy transmission coefficient of the nozzle for the HAT rig with different exit pressures and hence different shock strengths as a function of Helmholtz number $\Omega=L \omega / \bar{c}$, where $L$ and $\bar{c}$ are respectively, the length and average mean sound speed of the subsonic part of the divergent section.

Figure 9 also shows two distinct frequency zones for a given shock strength: as the frequency increases up to a critical frequency the dissipation decreases substantially. As the nozzle becomes less compact, a further increase in frequency increases the dissipation. The critical frequencies found to be 510,530,580, 650 and $680 \mathrm{~Hz}$, respectively, for upstream Mach numbers of $\bar{M}_{3}=1.22,1.41,1.68,2$ and 2.23. Figure 9 shows that for frequencies higher than critical, the dissipation has a more complicated dependency on frequency with peaks and troughs. This is due to resonances of the nozzle and can be related to the Helmholtz number $\Omega=L \omega / \bar{c}$ of the divergent section of the nozzle, where $\overline{\mathrm{c}}$ denotes the average speed of sound in the divergent section and $\mathrm{L}$ is its length. When the transmission coefficients are plotted as a functions of $\Omega$ (see figure 10), they collapse onto a single curve and are virtually indistinguishable. The critical frequency is found to be $\Omega=L \omega / \bar{c}=2.5$.

\section{Parametric study - noncompact nozzles}

In this section we study the effect of the length of the divergent section of the nozzle on the transmission and dissipation of the acoustic energy through the HAT rig nozzle. Results are shown in figure 11 for different lengths of the divergent section decreasing from the actual length of $340 \mathrm{~mm}$ to $70 \mathrm{~mm}$. 


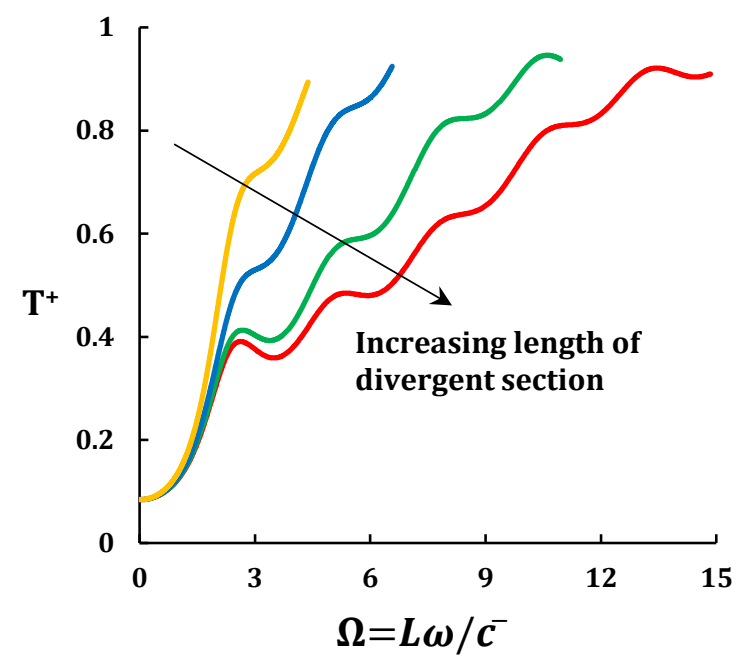

(a) Energy transmission coefficient

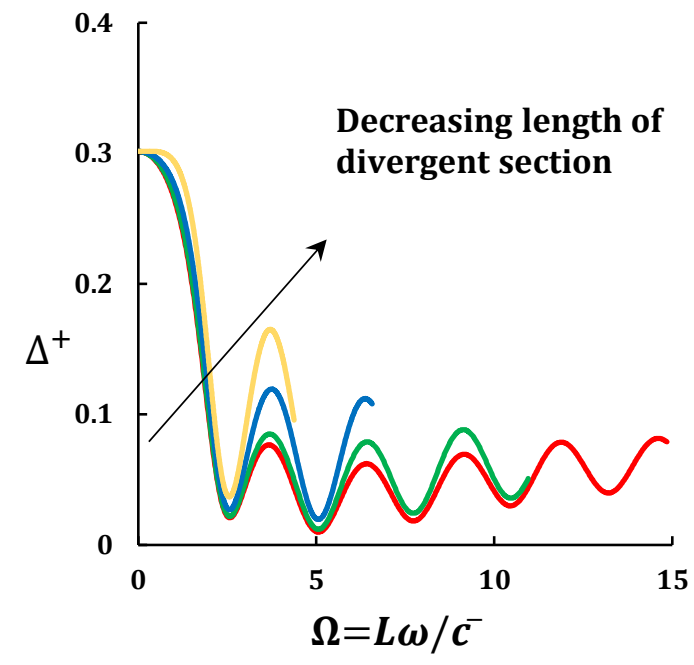

(b) Acoustic energy dissipation coefficient

Fig. 11 (a) Energy transmission and (b) dissipation coefficients of the nozzle as a function of frequency obtained using LOTAN for HAT rig with different lengths of the divergent section LDivergent $=340 \mathrm{~mm}($ red line $)$, LDivergent $=250 \mathrm{~mm}($ green line $)$, LDivergent $=150 \mathrm{~mm}$ (blue line $)$ and LDivergent $=100 \mathrm{~mm}$ (yellow line).

For a frequencies up to about $\Omega=2.5$ as the nozzle becomes more compact the transmission of the acoustic energy decreases (figure 11(a)) and the dissipation of the energy increases (figure 11(b)), indicating that the shock has dissipated more acoustic energy into entropy fluctuations in the choked compact nozzle. Figure 11 also shows that for each length of the divergent section there is a critical frequency above which resonances are observed in the transmission coefficient. As discussed earlier this resonance frequency is related to the length and average speed of sound in the divergent section and found to be $\Omega=L \omega / \bar{c}=2.5$. Above the critical frequency, the transmission and dissipation depend on nozzle length not only through the non-dimensional frequency $\Omega$ but also through the aspect ratio of diameter/length. 


\section{Direct and indirect noise in a model combustor}

In this section we use the low order model presented in section II to study direct and indirect (entropy and vorticity) noise in a model combustor. We consider an idealised combustor shown schematically in figure 12 with non-reflecting boundary conditions at inlet and exit. The approach can readily be extended for any inlet and outlet boundary conditions. Here since, we are interested in determining the contribution of perturbations generated at the flame to the pressure perturbations in the downstream duct, the inlet and outlet boundaries (at positions 0 and 6 in Fig. 12) are taken to be non-reflecting (Mahmoudi et al. 2015 [11]). The combustor is composed of a straight thin-annular duct attached to a nozzle. Downstream of the nozzle the straight duct is also thin-annular. We assume that a normal shock is present in the divergent section of the nozzle. The energy of flow is increased across $x=0$ by the rate of heat input, $Q=\bar{Q}+Q^{\prime}$. The mean heat release rate, $\bar{Q}$ is defined by specifying the rise in the mean stagnation temperature after combustion. The linear fluctuations in the rate of heat input have a forced frequency $\omega$ and azimuthal mode number $n$ and are denoted by $Q^{\prime}(t)=\hat{Q} e^{i \omega t+i n \theta}$. The inlet mean flow is prescribed by setting the pressure, temperature and mass flux.

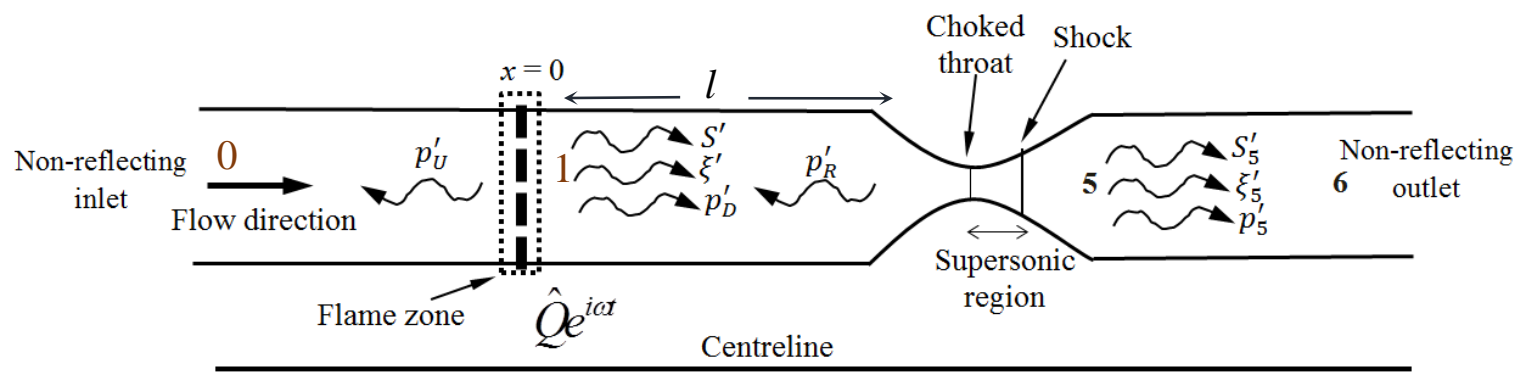

Fig. 12 Simplified model of a combustor.

Upstream of the flame there is only an upstream propagating acoustic wave $\left(\mathrm{p}_{\mathrm{U}}^{\prime}\right)$. Downstream of the flame, acoustic $\left(\mathrm{p}_{\mathrm{D}}^{\prime}\right)$, entropy $\left(\mathrm{S}^{\prime}\right)$ and vorticity $\left(\xi^{\prime}\right)$ waves produced by the flame, travel downstream toward the nozzle contraction, where they are partially reflected to give an upstream propagating wave $\left(\mathrm{p}_{\mathrm{R}}^{\prime}\right)$. This interacts with the flame to produce a transmitted wave altering the wave upstream of the flame in $x<0$. It also alters the downstream propagating acoustic, entropic and vortical waves propagating towards the nozzle outlet. We wish to obtain the ratio of direct to indirect noise in the downstream duct.

To calculate the direct sound, we calculate the entropy and vorticity waves generated at the flame but ignore their contribution when applying the downstream boundary condition. The direct sound field is obtained by adding 
the downstream and upstream propagating acoustic waves. The indirect noise due to the entropy and vorticity waves can be determined by subtracting the direct noise from the full sound field calculated.

The geometry considered in the numerical simulation is similar to that considered in [1] and summarized in Table 4. We consider the inlet static pressure and static temperature to be 12 bar and $653 \mathrm{~K}$ respectively [1].

Table 4 Summary of the geometry for model combustor [1]

Axial position of the flame, $x=0.0$

Mean radius of ducts, $r=0.3 \mathrm{~m}$

Total cross-sectional area in upstream and downstream straight ducts, $a=0.3 \mathrm{~m}^{2}$

Distance between the flame and the nozzle inlet, $l=0.5 \mathrm{~m}$

Nozzle length, $L=0$ (compact)

The transfer function $|\hat{p} / \hat{Q}|$ as a function of frequency for plane wave is shown in figure 13 for an inlet Mach number of $\overline{\mathrm{M}}_{0}=0.06$ and stagnation temperature ratio across the flame zone of $\overline{\mathrm{T}}_{01} / \overline{\mathrm{T}}_{00}=3$. At both nozzle inlet and combustor outlet resonances are observed in the direct and indirect sound, though with different frequency intervals between the peaks and troughs. For the plane acoustic wave the gap between resonant frequencies to be about $f=\overline{\mathrm{c}}_{1} /(2 l) \mathrm{Hz}$ where $\overline{\mathrm{c}}_{1}$ is the mean sound speed is downstream of the flame zone (at position 1 in Fig.

12). This resonant frequency is approximately $800 \mathrm{~Hz}$ for the conditions in figure 13. For the indirect entropy noise, the gap between peaks occurs in much smaller frequency interval $\bar{u}_{1} / l \mathrm{~Hz}$ (approximately $170 \mathrm{~Hz}$ for the conditions in figure 13). At all frequencies, the direct noise at the nozzle inlet is almost one order of magnitude higher than in the duct just downstream of the nozzle.

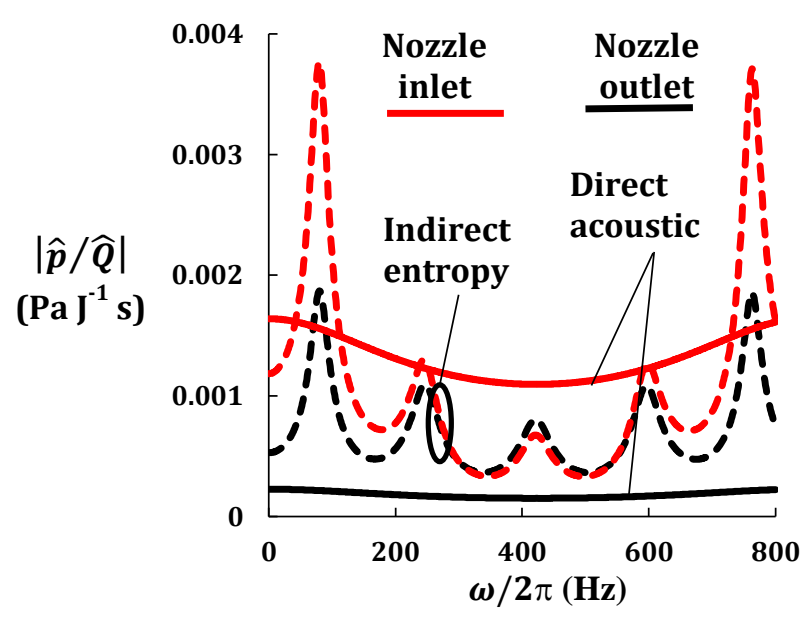

Fig. 13 Magnitude of the indirect entropy noise (dashed line) and direct noise (solid line) as a function of frequency obtained for plane wave $(n=0), \overline{\mathbf{M}}_{0}=0.06$ and $\bar{T}_{01} / \bar{T}_{00}=3.0$ at the nozzle inlet (red line) and at nozzle outlet (black line). 
This is because in a low Mach number mean flow, the choked boundary condition approximates to a hard end boundary condition for an incident plane sound wave. This leads to reflection of most of the incident energy, and hence only a small amount propagates through the nozzle into the downstream duct.

In contrast, the indirect noise is of similar in magnitude at the nozzle inlet and at outlet and as a result, the indirect noise is higher than the direct noise at the nozzle outlet in the frequency range considered.

The results for circumferential wavenumber $n=1$ are shown in figure 14 . Results for higher circumferential mode of $n=2$ is similar to those of $n=1$ and hence we do not show them separately. At both locations it is seen that for frequencies below the cut-off frequency $(\sim 450 \mathrm{~Hz})$ the acoustic waves are cut-off and thus their magnitude is exponentially small away from their source. At the cut-off frequency, the direct acoustic, indirect entropy and vorticity noise each take their maximum value, and even the magnitude of the vorticity noise is nearly comparable to that of the direct acoustic noise; at other frequencies it is negligible. The indirect entropy noise is higher than the two other noise components. For frequencies above cut-off, the acoustic waves are propagating and so their magnitude is independent of position in the straight ducts. The magnitude of the indirect waves varies with frequency due to resonances. At the nozzle inlet the magnitude of the indirect entropy noise is less than the direct noise except at its resonant frequency (Fig. 14a). We see from Fig. 14b that at the nozzle exit, the indirect entropy noise is usually higher than the direct noise except at its anti-resonances.

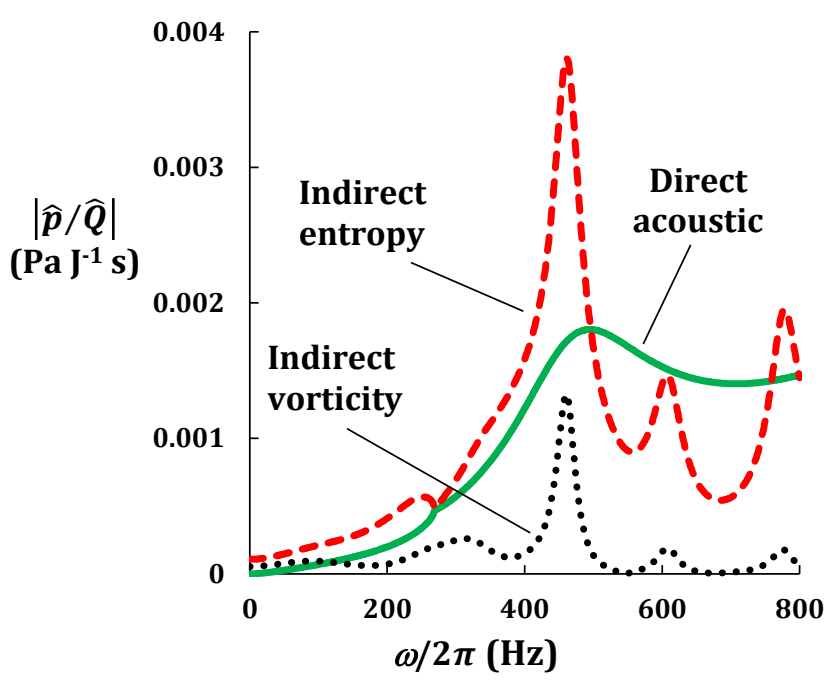

(a) Nozzle inlet 


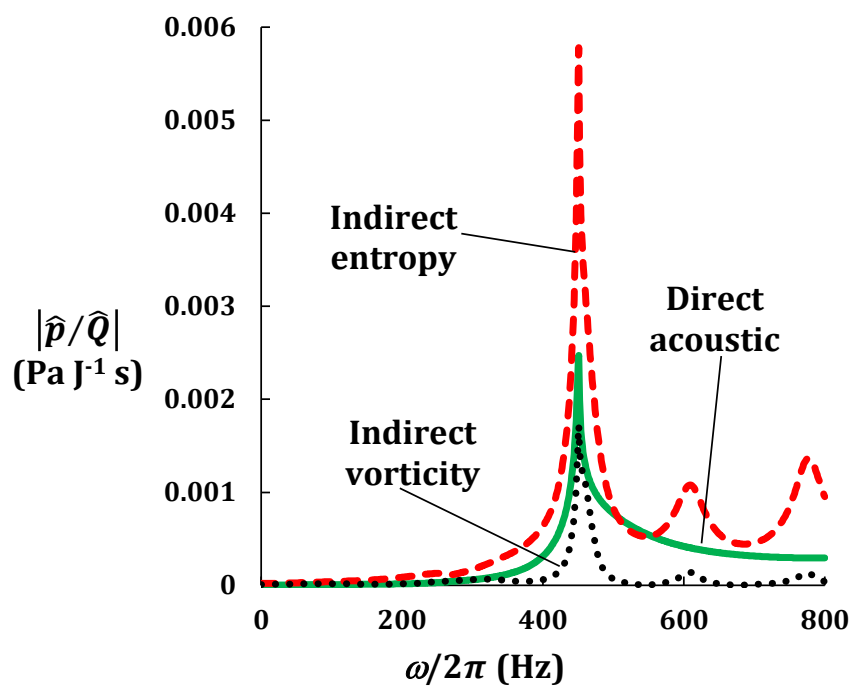

(b) Nozzle outlet

Fig. 14 Magnitude of the indirect entropy noise (dashed line) and direct noise (solid line) as a function of frequency obtained for circumferential wave $(n=1), \bar{M}_{0}=0.06$ and $\bar{T}_{01} / \bar{T}_{00}=3.0$ (a) at the nozzle inlet and (b) at the nozzle outlet.

\section{Conclusions}

The transmission of the acoustic and entropic waves through a convergent-divergent nozzle is studied using a low-order model, the LOTAN code. The analysis was performed both for a subsonic nozzle and for a choked nozzle where a normal shock wave exists in the downstream divergent section of the nozzle. In order to examine the validity of the low order model (LOTAN code) in predicting the nozzle flow, the EWG and HAT rigs of DLR were modelled and the results predicted by LOTAN were compared against experimental measurements. In the choked case the supersonic region between the nozzle throat and the normal shock was assumed to be acoustically compact. The results presented for EWG and HAT rigs were in excellent agreement with experiments. Having validated the modelling approach, the model was used to undertake a parametric study and to investigate the ratio of direct and indirect noise within a model combustor and transmitted downstream of a choked nozzle.

For the HAT rig with acoustic waves incident on the nozzle, the energy transmission, reflection and dissipation coefficients obtained using LOTAN were compared with experimental data. For low frequencies below $500 \mathrm{~Hz}$ and for a choked nozzle it was observed that part of the acoustic energy is dissipated into convected entropy fluctuations due to the normal shock in the divergent section of the nozzle. Decreasing the mean outlet pressure to increase the shock strength was found to result in increased dissipation of the acoustic energy. For a given shock strength, the fraction of incident acoustic energy is dissipated due to the shock wave decreases dramatically as the frequency increases up to a critical frequency at which the nozzle becomes non-compact. The critical frequency is found to be related to length of the divergent section, $L$ and the average speed of sound in the 
divergent section $\bar{c}$, and given by non-dimensional frequency $\Omega=L \omega / \bar{c} \approx 2.5$ for all the shock strengths studied. Above this critical frequency, the dissipation coefficient oscillates as the non-dimensional frequency varies. The effect of varying the length of the divergent section was studied. It was found that as the nozzle becomes shorter the acoustic energy dissipation at a given value of non-dimensional frequency $\Omega$, increases. The energy transmission coefficient was found to depend primarily on the non-dimensional frequency $\Omega$ and only weekly on the shock strength. It increases with $\Omega$.

The relative magnitudes of the direct and indirect combustion noise were determined for an idealised combustor using analytical and low-order models. The idealised combustor consists of a flame within a thin annular duct with a converging-diverging choked nozzle at the combustor exit. There is a second annular duct of the same cross-sectional area as the combustor downstream of the nozzle. The combustor inlet has assumed to be non-reflecting although the approach can be readily extended to general inlet conditions.

The results of the low-order model show that resonance leads to a complex dependency of the indirect entropy and vorticity noise to frequency. They have low frequency resonances associated with the time taken for linear disturbances to convect from the flame front to the nozzle and a reflected acoustic wave to travel back. The direct acoustic waves are significantly attenuated by the nozzle: their pressure perturbations at the nozzle outlet are an order of magnitude smaller than those at the nozzle inlet. While, the entropy and vorticity indirect noise at the nozzle outlet is close to that at the nozzle inlet. The magnitude of the indirect vorticity noise found to be negligible compared to the indirect entropy and direct acoustic noise. For a choked nozzle between two ducts with low Mach number flows, the magnitude of the direct noise downstream of the nozzle is much smaller than the indirect entropy noise and thus the indirect entropy noise is the main mechanism of noise generation at the downstream duct.

\section{Acknowledgements}

This work was funded by the European Commission whose financial support is gratefully acknowledged. It is part of the RECORD (Research on Core Noise Reduction) project under Grant No. RG66913. The authors also gratefully acknowledge Dr. Friedrich Bake and Dr. Karsten Knobloch from DLR for making the experimental data available.

\section{References}


[1] Dowling, A. P., and Mahmoudi, Y., “Combustion noise," Proceedings of the Combustion Institute, Vol. 35, No. 1, 2015, pp. 65-100.

[2] Duran, I., Moreau, S., Nicoud, F., Livebardon, T., Bouty, E., and Poinsot, T., “Combustion noise in modern aero-engines," Aerospace Lab Journal, Vol. 7, 2014, pp. 1-11.

[3] Liu, Y., Dowling, A. P., Swaminathan, N., Morvant, R., Macquisten, M. A. and Caracciolo, L. F., "Prediction of combustion noise for an aeroengine combustor," Journal of Propulsion and Power, Vol. 30, No. 1, 2013, pp. 114-122.

[4] Dowling, A. P., and Stow, S. R., “Acoustic analysis of gas turbine combustors," Journal of propulsion and power, Vol. 19, No. 5, 2003, pp. 751-764.

[5] Lieuwen, T., and Yang, V. (eds.), Combustion Instabilities in Gas Turbine Engines. Operational Experience, Fundamental Mechanisms, and Modeling, Vol. 210, Progress in Astronautics and Aeronautics, AIAA, Reston, VA, 2005.

[6] Marble, F. E., and Candel, S. M., “Acoustic disturbance from gas non-uniformities convected through a nozzle,” Journal of Sound and Vibration, Vol. 55, No. 2, 1977, pp. 225-243.

[7] Strahle, W. C., "Combustion noise," Progress in Energy and Combustion Science, Vol. 4, No. 3, 1978, pp. 157-176.

[8] Morfey, C. L., "Amplification of aerodynamic noise by convected flow inhomogeneities," Journal of Sound and Vibration, Vol. 31, No. 4, 1973, pp. 391-397.

[9] Strahle, W.C., “On combustion generated noise,” Journal of Fluid Mechanics, Vol. 49, 1971, pp. 399-414.

[10] Bell, W. A., Daniel, B. R., and Zinn, B.T., "Experimental and theoretical determination of the admittances of a family of nozzles subjected to axial instabilities," Journal of Sound and Vibration, Vol. 30, No. 2, 1973, pp. 179-190.

[11] Mahmoudi, Y., Dowling, A. P., and Stow, S., "Direct and Indirect Combustion Noise in an Idealised Combustor," 25th International Colloquium on the Dynamics of Explosions and Reactive Systems (ICDERS), Leeds, UK, 2015.

[12] Morgans, A. S., Duran, I., "Entropy noise: A review of theory, progress and challenges," International Journal of Spray and Combustion Dynamics, Vol. 0, No. 0, 2016, pp. 1-14.

[13] Howe, M. S., “Indirect combustion noise,” Journal of Fluid Mechanics,” Vol. 659, 2010, pp. 267-288.

[14] Goh, C. S. and Morgans, A. S., "The influence of entropy waves on the thermoacoustic stability of a model combustor," Combustion Science and Technology, Vol. 185, No. 2, 2013, pp. 249-268.

[15] Leyko, M., Nicoud, F., and Poinsot, T., "Comparison of direct and indirect combustion noise mechanisms in a model combustor,” AIAA Journal, Vol. 47, No. 11, 2009, pp. 2709-2716.

[16] Leyko, M., Moreau, S., Nicoud, F., and Poinsot, T., "Numerical and analytical modelling of entropy noise in a supersonic nozzle with a shock," Journal of Sound and Vibration, Vol. 330, No. 16, 2011, pp. 3944-3958.

[16] Leyko, M., Nicoud, F., Moreau, S., and Poinsot, T., "Numerical and analytical investigation of the indirect combustion noise in a nozzle," Comptes Rendus Mécanique, Vol. 337, No. 6, 2009, pp.415-425.

[18] Stow, S.R., Dowling, A. P., and Hynes, T.P., "Reflection of circumferential modes in a choked nozzle,” Journal of Fluid Mechanics, Vol. 467, 2002, pp. 215-239. 
[19] Cumpsty, N. A. and Marble, F.E., "Core noise from gas turbine exhausts," Journal of Sound and Vibration, Vol. 54, No. 2, 1977, pp. 297-309.

[20] Cumpsty, N. A. and Marble, F. E., "The interaction of entropy fluctuations with turbine blade rows; a mechanism of turbojet engine noise," Proceedings of the Royal Society of London A: Mathematical, Physical and Engineering Sciences, Vol. 357, No. 1690, 1977, November, pp. 323-344.

[21] Cumpsty, N. A., "Jet engine combustion noise: pressure, entropy and vorticity perturbations produced by unsteady combustion or heat addition," Journal of Sound and Vibration, Vol. 66, No. 4, 1979, pp. 527-544.

[22] Goh, C. S. and Morgans, A. S., "Phase prediction of the response of choked nozzles to entropy and acoustic disturbances," Journal of Sound and Vibration, Vol. 330, No. 21, 2011, pp. 5184-5198.

[23] Duran, I., and Moreau, S., "Solution of the quasi-one-dimensional linearized Euler equations using flow invariants and the Magnus expansion,” Journal of Fluid Mechanics, Vol. 723, 2013, pp. 190-231.

[24] Moase, W. H., Brear, M. J., and Manzie, C., “The forced response of choked nozzles and supersonic diffusers,” Journal of Fluid Mechanics, Vol. 585, 2007, pp. 281-304.

[25] Giauque, A., Huet, M., and Clero, F., "Analytical analysis of indirect combustion noise in subcritical nozzles," Journal of Engineering for Gas Turbines and Power, Vol. 134, No. 11, 2012, pp. 111202.

[26] Duran, I., and Morgans, A. S., "On the reflection and transmission of circumferential waves through nozzles," Journal of Fluid Mechanics, Vol. 773, 2015, pp. 137-153.

[27] Muthukrishnan, M., Strahle, W. C., and Neale, D. H., "Separation of hydrodynamic, entropy, and combustion noise in a gas turbine combustor," AIAA Journal, Vol. 16, No. 4, 1978, pp. 320-327.

[28] Bake, F., Michel, U., Röhle, I., Richter, C., Thiele, F., Liu, M., and Noll, B., "Indirect combustion noise generation in gas turbines," 11th AIAA/CEAS Aeroacoustics Conference, Monterey, CA, Vol. 2830, 2005.

[29] Bake, F., Richter, C., Mühlbauer, B., Kings, N., Röhle, I., Thiele, F., and Noll, B., "The Entropy Wave Generator (EWG): A Reference Case on Entropy Noise,” Journal of Sound and Vibration, Vol. 326, No. 3, 2009, pp. 574-598.

[30] Bake, F., Kings, N., Fischer, A., and Röhle, I., "Experimental investigation of the entropy noise mechanism in aeroengines," International Journal of Aeroacoustics, Vol. 8, No. 1, 2009, pp. 125-142.

[31] Kings, N., Enghardt, L., and Bake, F., "Indirect Combustion Noise: Experimental Investigation of the Vortex Sound Generation in a Choked Convergent-divergent Nozzle," Société Française d'Acoustique, Acoustics 2012, Nantes, France, 2012.

[32] Knobloch, K., Werner, T., and Bake, F., "Noise generation in hot nozzle flow," Proceedings of ASME Turbo Expo 2015 : Turbine Technical Conference and Exposition, Montr'eal, Canada, June 15 - 19, 2015.

[33] Mühlbauer, B., Noll, B., and Aigner, M., "Numerical investigation of the fundamental mechanism for entropy noise generation in aero-engines," Acustica united with Acustica, Vol. 95, No. 3, 2009, pp. 470-487.

[34] Durán, I., Moreau, S., and Poinsot, T., "Analytical and numerical study of combustion noise through a subsonic nozzle," AIAA Journal, Vol. 51, No. 1, 2012, pp. 42-52. 
[35] Ullrich, W. C., and Sattelmayer, T., "Transfer Functions of Acoustic, Entropy and Vorticity Waves in an Annular Model Combustor and Nozzle for the Prediction of the Ratio Between Indirect and Direct Combustion Noise," 21st AIAA/CEAS Aeroacoustics Conference, 2015, p. 2972.

[36] Stow, S. R., and Dowling, A. P., “A time-domain network model for nonlinear thermoacoustic oscillations,” Journal of engineering for gas turbines and power, Vol. 131, No. 3, 2009, p. 031502.

[37] Stow, S. R., and Dowling, A. P., "Thermoacoustic oscillations in an annular combustor," ASME Turbo Expo 2001: Power for Land, Sea, and Air (pp. V002T02A004-V002T02A004), American Society of Mechanical Engineers, June 2001. 